\title{
Ventricular dilatation in the absence of ACE inhibitors: influence of haemodynamic and neurohormonal variables following myocardial infarction
}

\author{
J T Walsh, P D Batin, M Hawkins, D McEntegart, A J Cowley
}

\begin{abstract}
Objective-To examine the relation between patterns of ventricular remodelling and haemodynamic and neurohormonal variables, at rest and during symptom limited exercise, in the year following acute myocardial infarction in patients not receiving angiotensin converting enzyme (ACE) inhibitors.
\end{abstract}

Design-A prospective observational study.

Patients-65 patients recruited following hospital admission with a transmural anterior myocardial infarction.

Methods-Central haemodynamics and neurohormonal activation at rest and during symptom limited treadmill exercise were measured at baseline before hospital discharge, one month later, and at three monthly intervals thereafter. Patients were classified according to individual patterns of change in left ventricular end diastolic volumes at rest, assessed at each visit using transthoracic echocardiography.

Results-In most patients ( $n=43,66 \%$ ) ventricular volumes were unchanged or reduced. Mean (SEM) treadmill exercise capacity and peak exercise cardiac index increased at month 12 by 200 (24) seconds $(\mathrm{p}<0.001 v$ baseline) and by $0.8(0.4)$ $1 / \mathrm{min} / \mathrm{m}^{2}$ ( $\mathrm{p}<0.05 v$ baseline), respectively, in this group. In patients with limited ventricular dilatation $(n=11,17 \%)$ exercise capacity increased by 259 (52) seconds (p $<0.001 v$ baseline) and peak exercise cardiac index improved by $0.8 \quad(0.7)$ $1 / \mathrm{min} / \mathrm{m}^{2}$ (NS). In the remaining $11 \mathrm{pa}-$ tients with progressive left ventricular dilatation, exercise capacity increased by 308 (53) seconds ( $p<0.001 v$ baseline) and peak exercise cardiac index similarly improved by $1.3(0.7) \quad 1 / \mathrm{min} / \mathrm{m}^{2}$ (NS). There were trends towards increased atrial natriuretic factor (ANF) secretion at rest and at peak exercise in this group. Conclusions-Ventricular dilatation after acute myocardial infarction is a heterogeneous process that is progressive in only a minority of patients. Compensatory mechanisms, including ANF release, appear capable of maintaining and improving exercise capacity in most patients for at least 12 months, even in those with a progressive increase in ventricular size. (Heart 1999;81:33-39)
Keywords: ventricular remodelling; myocardial infarction; neurohormones; atrial natriuretic factor

Left ventricular volume is a powerful predictor of survival in patients with ischaemic heart disease. ${ }^{12}$ Changes in ventricular function and geometry ("ventricular remodelling") following acute myocardial infarction are heterogeneous and poorly understood. Early dilatation of the left ventricle appears compensatory but when this process is progressive ventricular impairment often occurs. ${ }^{3-5}$ There are few long term studies of the changes in ventricular volume following myocardial infarction and thus the timing of the underlying pathophysiological mechanisms remain unclear. Alterations in the haemodynamic and neurohormonal indices that are known to occur after acute myocardial infarction are likely to be contributory factors.

The haemodynamic consequences of ventricular dilatation at rest have been investigated in previous studies. However, resting haemodynamic variables are poor predictors of exercise capacity. ${ }^{6}$ The impact of ventricular remodelling on haemodynamics during symptom limited maximum exercise testing has not been assessed. The significance of long term neurohormonal activation in relation to ventricular remodelling is unknown. In the early phase following acute myocardial infarction, neurohormonal activation is likely to be compensatory but appears to be deleterious when prolonged. Increases in plasma catecholamines, renin activity, and atrial natriuretic factor (ANF) after myocardial infarction are all associated with a poor prognosis. ${ }^{8-10}$ We have previously shown that measuring neuroendocrine indices during exercise after myocardial infarction gives additional information to measurements obtained at rest. ${ }^{11}$

In this study we examined the relation between patterns of ventricular remodelling and haemodynamic and neurohormonal indices at rest and during symptom limited exercise in the year following acute myocardial infarction.

\section{Methods}

PATIENTS

Sixty five patients (five female, 60 male) entered the study following their first transmural anterior myocardial infarction. Their mean age was 64 years (range 39 to 74). Patients over the age of 75 years were excluded. Baseline studies were performed a mean (SEM) of 13 
Table 1 Demographic data for patients at baseline

\begin{tabular}{llll}
\hline & $\begin{array}{l}\text { No dilatation } \\
(n=43)\end{array}$ & $\begin{array}{l}\text { Limited dilatation } \\
(n=11)\end{array}$ & $\begin{array}{l}\text { Progressive } \\
\text { dilatation }(n=11)\end{array}$ \\
\hline Age (years) & $64(3)$ & $65(2)$ & $64(2)$ \\
Sex (M:F) & $41: 2$ & $11: 0$ & $8: 3$ \\
BSA (m) & $2.0(0.5)$ & $1.92(0.4)$ & $1.96(0.6)$ \\
Peak CK (IU/1) & $4107(234)$ & $4121(200)$ & $4192(200)$ \\
Thrombolysis (n) & $35(81 \%)$ & $10(91 \%)$ & $8(73 \%)$ \\
Diuretic (n) & $11(26)$ & $2(18)$ & $2(18)$ \\
Flosequinan (n) & $20(47)$ & $6(54)$ & $6(54)$ \\
$\beta$ Blocker (n) & $21(49 \%)$ & $8(73 \%)$ & $5(45 \%)$ \\
Exercise time (s) & $1014(35)$ & $1040(73)$ & $834(64)$ \\
\hline
\end{tabular}

Values are mean (SEM) unless specified otherwise.

BSA, body surface area; CK, creatinine kinase.

Table 2 Reasons for patients failing to enter study

\begin{tabular}{llll}
\hline & $\begin{array}{l}\text { No } \\
\text { dilatation }\end{array}$ & $\begin{array}{l}\text { Limited } \\
\text { dilatation }\end{array}$ & $\begin{array}{l}\text { Progressive } \\
\text { dilatation }\end{array}$ \\
\hline Angina & 1 & 0 & 0 \\
Non-compliance & 3 & 0 & 0 \\
Other illness & 0 & 0 & 1 \\
Medication change & 5 & 0 & 1
\end{tabular}

(2) days after admission. Patients were reassessed one, three, six, and 12 months after the baseline study. Myocardial infarction was defined by an episode of chest pain associated with the development of Q waves on the ECG, and a rise in the plasma creatine kinase to more than twice the upper limit of normal for our laboratory (normal range 25 to $200 \mathrm{IU} / \mathrm{l}$ ). Creatine kinase was recorded daily for three days from admission, and the highest value noted. Patients with severe heart failure or ongoing ischaemia (defined as anginal pain on exertion resulting in termination of exercise testing owing to symptoms or ECG changes) were excluded.

Drug treatment at baseline was prescribed independently, at the discretion of the admitting consultant physician responsible for the patient. All patients were also participating in a double blind, placebo controlled trial of the effects of flosequinan in patients following myocardial infarction. Drug treatment prescribed at entry comprised $\beta$ blockers (timolol, $\mathrm{n}=24$; atenolol, $\mathrm{n}=6)$ and diuretics $(\mathrm{n}=15)$, up to $80 \mathrm{mg}$ of frusemide (or equivalent). Diuretics and $\beta$ blockers were not prescribed concurrently. $\beta$ Blockers were prescribed for routine postinfarction prophylaxis or preexisting hypertension. Patients taking angiotensin converting enzyme (ACE) inhibitors or nitrates were excluded, as studies published

Table 3 Baseline and changes from baseline in left ventricular volume

\begin{tabular}{llll}
\hline & $\begin{array}{l}\text { No dilatation } \\
(n=43)\end{array}$ & $\begin{array}{l}\text { Limited dilatation } \\
(n=11)\end{array}$ & $\begin{array}{l}\text { Progressive } \\
\text { dilatation }(n=11)\end{array}$ \\
\hline $\begin{array}{l}\text { Baseline LVEDVI }\left(\mathrm{ml} / \mathrm{m}^{2}\right) \\
\Delta \text { LVEDVI }\left(\mathrm{ml} / \mathrm{m}^{2}\right)\end{array}$ & $94.3(4.8)$ & $83.2(9.5)$ & $81.4(7.7)$ \\
$\quad$ Month 1 & $-19.2(4.3)^{\star \star \star}$ & $26.8(8.6)^{\star \star}$ & $3.6(8.6)$ \\
Month 3 & $-20.5(4.3)^{\star \star \star}$ & $16.0(8.6)$ & $9.6(8.6)$ \\
Month 6 & $-18.0(4.3)^{\star \star \star}$ & $9.6(8.6)$ & $37(8.6)^{\star \star \star}$ \\
Month 12 & $-22.1(4.6)^{\star \star \star}$ & $-13.7(8.8)$ & $36.3(9.0)^{\star \star \star}$ \\
Baseline LVESVI $\left(\mathrm{ml} / \mathrm{m}^{2}\right)$ & $62.8(3.6)$ & $54.1(6.4)$ & $53.7(6.3)$ \\
$\Delta$ LVESVI $\left(\mathrm{ml} / \mathrm{m}^{2}\right)$ & & & \\
Month 1 & $-14.1(3.4)^{\star \star \star}$ & $18.1(6.8)^{\star \star}$ & $5.0(6.8)$ \\
Month 3 & $-15.4(3.4)^{\star \star \star}$ & $11.6(6.8)$ & $10.2(6.8)$ \\
Month 6 & $-11.9(3.4)^{\star \star \star}$ & $7.1(6.8)$ & $38.4(6.8)^{\star \star \star}$ \\
Month 12 & $-13.7(3.6)^{\star \star \star}$ & $-8.4(6.9)$ & $26.3(7.1)^{\star \star \star}$ \\
\hline
\end{tabular}

Values are mean (SEM).

${ }^{\star \star} \mathrm{p}<0.01 ;{ }^{\star \star \star} \mathrm{p}<0.001 v$ baseline.

LVEDVI, left ventricular end diastolic volume index; LVESVI, left ventricular endsystolic volume index. around the time this study began had shown that these drugs may influence ventricular remodelling. ${ }^{12}{ }^{13}$ The onset of this study predated studies showing the beneficial effects of ACE inhibitors on mortality after myocardial infarction. ${ }^{14-18}$ Patients taking other vasoactive treatment for persisting ischaemia or heart failure were excluded.

\section{ECHOCARDIOGRAPHIC STUDIES}

Measurements of left ventricular volumes were assessed using cross sectional echocardiography. Echocardiograms were recorded at each visit immediately before exercise assessment and recorded on super VHS tape for later analysis. Patient angulation, transducer position, and respiratory phase were noted at baseline, and every attempt was made to reproduce these during subsequent follow up assessments. To minimise variability, echocardiograms were recorded and analysed for each patient by the same operator at each visit.

Analyses of the images were performed using a computer assisted, video overlay, echocardiographic analysis system (Thoraxcenter, Erasmus University, Rotterdam, the Netherlands). An apical four chamber view was used for imaging and a modified Simpson's single plane disc method for analysis. End diastolic and end systolic frames were selected and the endocardial outline of each traced with a digitising pad. End diastole was defined as the first frame after the start of the QRS complex and end systole as the frame immediately preceding mitral valve opening. The mean of three consecutive cardiac cycles was taken from each examination. ${ }^{12}$ Left ventricular end diastolic volume index (LVEDVI) and end systolic index (LVESVI) were derived by using the body surface area measured at each visit.

\section{DEFINITIONS}

Patients were classified according to individual patterns of change in LVEDVI and LVESVI over the 12 month period. Normal ranges within our laboratory were determined from 38 age matched controls. Mean (SEM) values for LVEDVI were $71.8(2.7) \mathrm{ml} / \mathrm{m}^{2}$ and for LVESVI, $39.3(2.3) \mathrm{ml} / \mathrm{m}^{2}$. The coefficient of repeatability determined from 16 control subjects having repeated echocardiograms at least one week apart for LVEDVI was 16.4 $\mathrm{ml} / \mathrm{m}^{2}$ and for LVESVI, $13.2 \mathrm{ml} / \mathrm{m}^{2}$.

Increases in LVEDVI were defined as an increase that was greater than the mean LVEDVI of the control subjects plus the coefficient of repeatability - that is, $88.2 \mathrm{ml} / \mathrm{m}^{2}$. Increased LVESVI was defined as an increase in LVESVI greater than the mean LVESVI of the control subjects plus the coefficient of repeatability - that is, $52.5 \mathrm{ml} / \mathrm{m}^{2}$. "Progressive dilatation" was defined as an increase in LVEDVI greater than the coefficient of repeatability $\left(16.4 \mathrm{ml} / \mathrm{m}^{2}\right)$ with an additional increase greater than the coefficient of repeatability on a subsequent occasion. Limited dilatation was defined as an initial end diastolic volume increase greater than $16.4 \mathrm{ml} / \mathrm{m}^{2}$ at month 1 , but no additional increase thereafter. "No dilatation" was defined as no increase in LVEDVI 
of more than $16.4 \mathrm{ml} / \mathrm{m}^{2}$ at any time from baseline. Increases and changes in LVESVI were defined in a similar way.

EXERCISE STUDIES

At the start of the study patients underwent repeated exercise testing until two consecutive

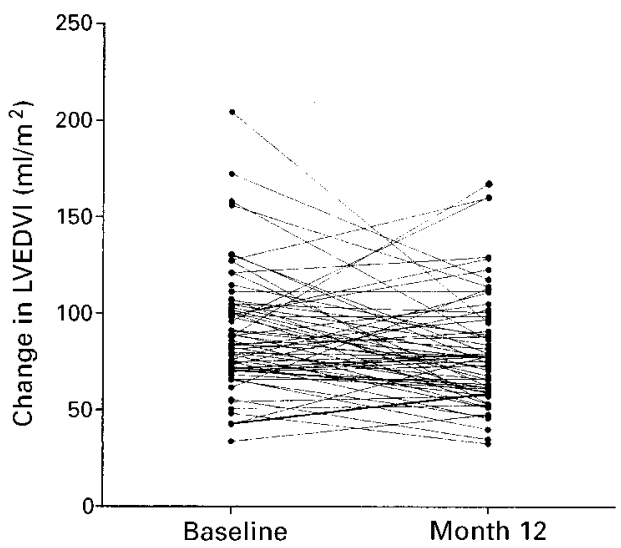

Figure 1 Individual change in left ventricular end diastolic volume following myocardial infarction.
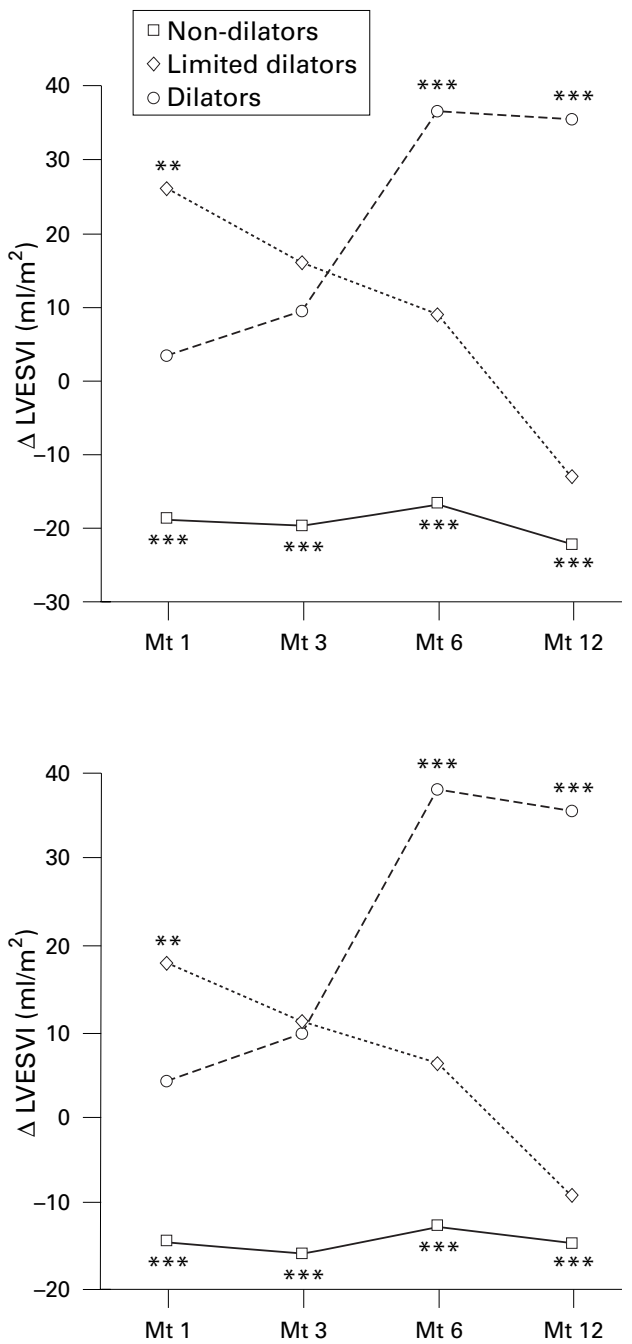

Figure 2 Changes in mean ventricular volumes after myocardial infarction. LVEDVI, left ventricular end diastolic volume index; LVESVI, left ventricular end systolic volume index. ${ }^{\star \star} p<0.01 ;{ }^{\star \star \star} p<0.001 v$ baseline.

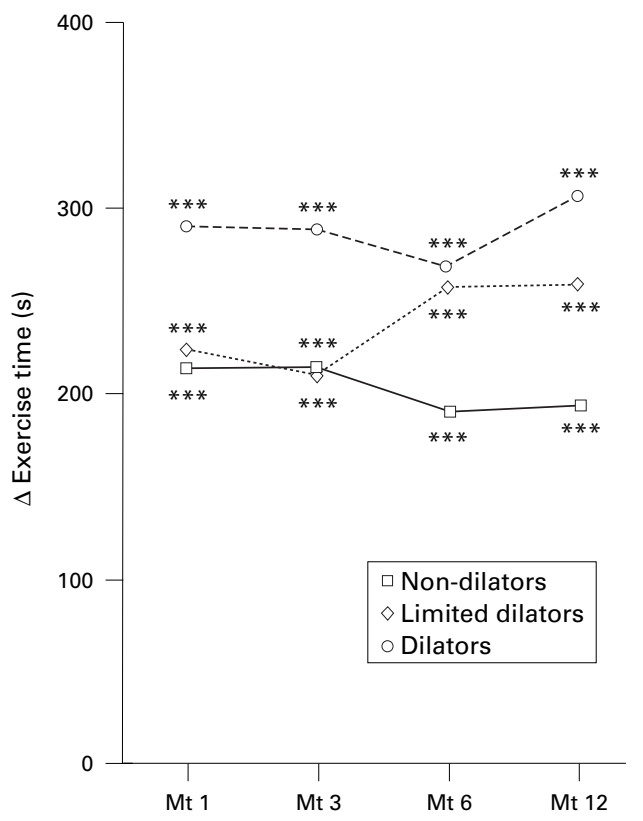

Figure 3 Change in mean exercise time from baseline after myocardial infarction. ${ }^{\star \star *} p<0.001 v$ baseline.

symptom limited exercise times did not increase by more than 5\%. Patients were reassessed one month from baseline and at three monthly intervals thereafter. Measurements were made after an overnight fast for morning visits, or after a light early breakfast for afternoon visits in a temperature controlled laboratory $\left(24-25^{\circ} \mathrm{C}\right)$. All patients completed a symptom limited exercise test with a modified Bruce protocol. ${ }^{19}$ Respiratory gases were continually monitored using a mass spectrometer (VG Medicals, Cheshire, UK) as previously reported. ${ }^{20}$

\section{CENTRAL HAEMODYNAMICS}

Cardiac index was measured at rest and during exercise by an indirect Fick principle; carbon dioxide was used as the indicator and respiratory gases were continually monitored with the mass spectrometer. ${ }^{20}$ Carbon dioxide production was calculated from the minute ventilation and mixed expired carbon dioxide concentration. The partial pressure of carbon dioxide in pulmonary venous blood was derived from end tidal carbon dioxide concentration, and the partial pressure in mixed venous blood was measured after a rebreathing manoeuvre. These three variables were then used to solve the Fick equation. The coefficient of repeatability of cardiac index in this group of patients at rest and during exercise was $0.8 \mathrm{ml} / \mathrm{min} / \mathrm{m}^{2}$ and $2.1 \mathrm{l} / \mathrm{min} / \mathrm{m}^{2}$ respectively.

Heart rate was measured by continuous electrocardiography. Mean arterial pressure and vascular resistance were calculated from standard formulae using blood pressure readings measured by auscultation with a sphygmomanometer.

\section{NEUROHORMONE STUDIES}

Measurements of resting neuroendocrine variables were made with the subject standing before exercise, from an intravenous cannula 
Table 4 Haemodynamic variables and neurohormonal measurements at baseline

\begin{tabular}{|c|c|c|c|c|c|c|}
\hline & \multicolumn{2}{|c|}{ No dilatation $(n=43)$} & \multicolumn{2}{|c|}{ Limited dilatation $(n=11)$} & \multicolumn{2}{|c|}{ Progressive dilatation $(n=11)$} \\
\hline & Rest & Exercise & Rest & Exercise & Rest & Exercise \\
\hline Heart rate (beats/min) & $69(3)$ & $109(4))$ & $61(4)$ & $113(7)$ & $72(4)$ & $111(7)$ \\
\hline $\mathrm{MAP}(\mathrm{mm} \mathrm{Hg})$ & $97(2)$ & $104(2)$ & $99(4)$ & $107(5)$ & 99 (3) & $112(6)$ \\
\hline Cardiac index $\left(1 / \mathrm{min} / \mathrm{m}^{2}\right)$ & $2.35(0.1)$ & $6.5(0.3)$ & $2.46(0.2)$ & $6.68(0.7)$ & $2.22(0.2)$ & $5.49(0.4)$ \\
\hline $\operatorname{SVI}\left(\mathrm{ml} / \mathrm{m}^{2}\right)$ & $36.6(2)$ & $65.9(2.8)$ & $43(3.9)$ & $72.4(7.9)$ & $32.3(3.2)$ & $52.3(4.9)$ \\
\hline Oxygen uptake (ml/min/kg) & $4.2(0.2)$ & $17.6(0.6)$ & $3.87(0.2)$ & $16.9(2.1)$ & $4.26(0.3)$ & $14.2(0.8)$ \\
\hline $\operatorname{SVR}\left(\right.$ dyn. $\left.\mathrm{cm}^{-5}\right)$ & $1802(67)$ & $737(40)$ & $1721(143)$ & $706(75)$ & $2029(179)$ & $949(102)$ \\
\hline \multirow[t]{2}{*}{$\mathrm{ANF}(\mathrm{pg} / \mathrm{ml})$} & $3.9(0.1)$ & $4.7(0.1)$ & $4.37(0.1)$ & $5.3(0.2)$ & $4.15(0.1)$ & $5(0.3)$ \\
\hline & 49 & 110 & 81 & 200 & 67 & 148 \\
\hline \multirow[t]{2}{*}{ Noradrenaline (pg/ml) } & $6.6(0.1)$ & $7.2(0.1)$ & $6.5(0.1)$ & $7.2(0.2)$ & $6.44(0.1)$ & $7.1(0.1)$ \\
\hline & 735 & 1339 & 665 & 1339 & 601 & 1211 \\
\hline \multirow{2}{*}{ Adrenaline (pg/ml) } & $4.26(0.1)$ & $4.9(0.1)$ & $4.53(0.2)$ & $5.2(0.2)$ & $4.04(0.3)$ & $4.5(0.2)$ \\
\hline & 74 & 134 & 90 & 185 & 55 & 90 \\
\hline \multirow[t]{2}{*}{$\operatorname{Renin}(\mathrm{ng} / \mathrm{ml} / \mathrm{h}$ Ang I) } & $-0.03(0.2)$ & $0.28(0.2)$ & $-0.57(0.3)$ & $0.04(0.3)$ & $0.03(0.3)$ & $0.3(0.4)$ \\
\hline & 0.97 & 1.3 & 0.57 & 1.04 & 1.03 & 1.34 \\
\hline
\end{tabular}

Values are mean (SEM) (haemodynamics) and log mean (SEM) (neurohormones). Geometric neurohormonal mean values are shown in bold.

ANF, atrial natriuretic factor; Ang, angiotensin; MAP, mean arterial pressure; SVI, stroke volume index; SVR, systemic vascular resistance.

inserted in the antecubital fossa. After the dead space of the cannula had been discarded, $25 \mathrm{ml}$ of blood were withdrawn for the assays of plasma renin activity (PRA), ANF, and the catecholamines noradrenaline and adrenaline.
Samples were similarly obtained immediately on completion of exercise and analysed using radioimmunoassay systems and high performance liquid chromatography with electrochemical detection, as previously reported. ${ }^{11}$

Table 5 Changes in haemodynamic variables and neurohormonal values from baseline at rest and during exercise

\begin{tabular}{|c|c|c|c|c|c|c|}
\hline & \multicolumn{2}{|c|}{ No dilatation $(n=43)$} & \multicolumn{2}{|c|}{ Limited dilatation $(n=11)$} & \multicolumn{2}{|c|}{ Progressive dilatation $(n=11)$} \\
\hline & Rest & Exercise & Rest & Exercise & Rest & Exercise \\
\hline \multicolumn{7}{|c|}{$\Delta$ Heart rate (beats/min) } \\
\hline Month 1 & $3(2)$ & $19(3)^{\star \star \star}$ & $1(4)$ & $12(6)^{\star}$ & $5(4)$ & $11(6)^{\star}$ \\
\hline Month 3 & $1(2)$ & $19(3)^{\star \star \star}$ & $6(4)$ & $10(6)$ & $5(4)$ & $20(6)^{\star \star \star}$ \\
\hline Month 6 & $1(2)$ & $15(3)^{\star \star \star}$ & $6(4)$ & $11(6)$ & $8(4)$ & $21(6)^{\star \star \star}$ \\
\hline Month 12 & $3(2)$ & $19(3)^{\star \star \star}$ & $8(4)$ & $15(6)^{\star \star}$ & $4(4)$ & $12(6)^{\star}$ \\
\hline \multicolumn{7}{|c|}{$\Delta$ Mean arterial pressure $(\mathrm{mm} \mathrm{Hg})$} \\
\hline Month 1 & $1.3(1.9)$ & $3.2(2.4)$ & $0.7(3.7)$ & $6.4(4.8)$ & $2.4(3.7)$ & $-1.2(4.8)$ \\
\hline Month 3 & $1.9(1.9)$ & $5.1(2.5)^{\star}$ & $4.6(3.7)$ & $2.3(4.8)$ & $0.1(3.7)$ & $0.2(4.8)$ \\
\hline Month 6 & $1.6(1.9)$ & $3.6(2.4)$ & $3.8(3.7)$ & $3.5(4.8)$ & $3.2(3.7)$ & $2.3(4.8)$ \\
\hline Month 12 & $3.6(2.0)$ & $8.3(2.6)^{\star \star}$ & $1.6(3.8)$ & $6.4(4.9)$ & $7.1(4.0)$ & $0.4(5.2)$ \\
\hline \multicolumn{7}{|c|}{$\Delta$ Cardiac index $\left(1 / \mathrm{min} / \mathrm{m}^{2}\right)$} \\
\hline Month 1 & $0.04(0.1)$ & $0.6(0.3)$ & $0.35(0.2)$ & $0.53(0.7)$ & $0.3(0.2)$ & $0.4(0.7)$ \\
\hline Month 3 & $0.09(0.1)$ & $1.1(0.4)^{\star \star}$ & $0.01(0.2)$ & $0.15(0.7)$ & $0.1(0.2)$ & $0.8(0.7)$ \\
\hline Month 6 & $0.11(0.1)$ & $0.8(0.3)^{\star}$ & $-0.01(0.2)$ & $0.6(0.7)$ & $0.2(0.2)$ & $0.7(0.7)$ \\
\hline Month 12 & $0.02(0.1)$ & $0.8(0.4)^{\star}$ & $-0.02(0.1)$ & $0.8(0.7)$ & $0.4(0.2)^{\star}$ & $1.3(0.7)$ \\
\hline \multicolumn{7}{|c|}{$\Delta$ Stroke volume index $\left(\mathrm{ml} / \mathrm{m}^{2}\right)$} \\
\hline Month 1 & $-2.5(1.7)$ & $-0.1 .7(3.2)$ & $3.0(3.4)$ & $-1.4(6.5)$ & $2.4(3.2)$ & $2.6(6.2)$ \\
\hline Month 3 & $-0.6(1.7)$ & $2.6(3.2)$ & $-5.7(3.4)$ & $-5.9(6.5)$ & $1.2(3.3)$ & $8.1(6.4)$ \\
\hline Month 6 & $0.2(1.7)$ & $3.4(3.2)$ & $-6.3(3.4)$ & $-0.02(6.5)$ & $1.1(3.2)$ & $1.4(6.2)$ \\
\hline Month 12 & $-2.6(1.8)$ & $0.9(3.4)$ & $-6.4(3.5)$ & $-3.0(6.7)$ & $4.1(3.5)$ & $16.7(7)^{\star}$ \\
\hline \multicolumn{7}{|c|}{$\Delta$ Stroke volume resistance $\left(\right.$ dyn. $\left.\mathrm{cm}^{-5}\right)$} \\
\hline Month 1 & $16(73)$ & $-33(43)$ & $-230(150)$ & $-8(89)$ & $-230(142)$ & $-67(84)$ \\
\hline Month 3 & $-35(74)$ & $-99(44)$ & $15.7(150)$ & $30(89)$ & $-58(146)$ & $32(84)$ \\
\hline Month 6 & $-104(73)$ & $-83(44)$ & $62.7(150)$ & $-63(89)$ & $-163(142)$ & $-73(85)$ \\
\hline Month 12 & $-118(78)$ & $-66(47)$ & $19.4(153)$ & $-66(85)$ & $-256(155)$ & $-195(94)^{\star}$ \\
\hline \multicolumn{7}{|c|}{$\Delta$ Oxygen uptake $(\mathrm{ml} / \mathrm{min} / \mathrm{kg})$} \\
\hline Month 1 & $-0.3(0.2)$ & $3(0.9)^{\star \star \star}$ & $0.25(0.4)$ & $5(1.8)^{\star \star}$ & $0.12(0.4)$ & $4.5(1.7)^{\star \star}$ \\
\hline Month 3 & $-0.1(0.1)$ & $4(0.9)^{\star \star \star}$ & $0.34(0.4)$ & $7(1.8)^{\star \star \star}$ & $0.09(0.4)$ & $3.4(1.7)^{\star}$ \\
\hline Month 6 & $-0.3(0.2)$ & $3(0.8)^{\star \star \star}$ & $0.03(0.4)$ & $6(1.8)^{\star \star \star}$ & $-0.02(0.4)$ & $3.8(1.7)^{\star}$ \\
\hline Month 12 & $-0.2(0.2)$ & $3(0.9)^{\star \star}$ & $0.05(0.4)$ & $6(1.8)^{\star \star \star}$ & $-0.16(0.4)$ & $4.3(1.8)^{\star}$ \\
\hline \multicolumn{7}{|c|}{$\Delta$ Atrial natriuretic factor $(\mathrm{pg} / \mathrm{ml})$} \\
\hline Month 1 & $-0.21(0.1)^{\star}$ & $-0.23(0.1)^{\star}$ & $-0.33(0.2)^{\star}$ & $0.13(0.2)$ & $-0.01(0.2)$ & $0.07(0.2)$ \\
\hline Month 3 & $-0.28(0.1)^{\star \star \star}$ & $-0.20(0.1)^{\star}$ & $-0.42(0.1)^{\star \star}$ & $-0.46(0.2)^{\star}$ & $-0.15(0.2)$ & $0.04(0.2)$ \\
\hline Month 6 & $-0.23(0.1)^{\star \star}$ & $-0.13(0.1)$ & $-0.65(0.2)^{\star \star \star}$ & $-0.42(0.2)$ & $0.07(0.2)$ & $0.1(0.2)^{\star}$ \\
\hline Month 12 & $-0.36(0.1)^{\star \star \star}$ & $-0.40(0.1)^{\star \star \star}$ & $-0.63(0.2)^{\star \star \star}$ & $-0.66(0.2)^{\star \star}$ & $-0.22(0.2)$ & $-0.28(0.2)^{\star \star}$ \\
\hline \multicolumn{7}{|c|}{$\Delta$ Noradrenaline $(\mathrm{pg} / \mathrm{ml})$} \\
\hline Month 1 & $0.21(0.1)$ & $0.39(0.1)^{\star \star \star}$ & $0.21(0.2)$ & $0.44(0.2)^{\star}$ & $0.20(0.2)$ & $0.13(0.2)$ \\
\hline Month 3 & $0.22(0.1)$ & $0.36(0.1)^{\star \star \star}$ & $0.38(0.2)$ & $0.33(0.3)$ & $0.07(0.2)$ & $0.40(0.2)^{\star}$ \\
\hline Month 6 & $0.12(0.1)$ & $0.23(0.1)^{\star \star}$ & $0.22(0.2)$ & $0.59(0.2)^{\star \star}$ & $0.06(0.2)$ & $0.20(0.2)$ \\
\hline Month 12 & $0.25(0.1)$ & $0.30(0.1)^{\star \star}$ & $0.10(0.2)$ & $0.39(0.2)^{\star}$ & $0.31(0.2)$ & $0.40(0.2)$ \\
\hline \multicolumn{7}{|c|}{$\Delta$ Adrenaline $(\mathrm{pg} / \mathrm{ml})$} \\
\hline Month 1 & $-0.11(0.2)$ & $0.12(0.1)$ & $0.02(0.3)$ & $0.27(0.3)$ & $0.38(0.4)$ & $0.48(0.3)$ \\
\hline Month 3 & $-0.15(0.2)$ & $0.04(0.1)$ & $-0.04(0.3)$ & $0.33(0.3)$ & $0.61(0.4)$ & $0.71(0.3)^{\star}$ \\
\hline Month 6 & $-0.1(0.2)$ & $0.20(0.1)$ & $-0.53(0.4)$ & $-0.10(0.3)$ & $0.49(0.4)$ & $0.33(0.3)$ \\
\hline Month 12 & $-0.13(0.2)$ & $0.13(0.2)$ & $-0.1(0.4)$ & $0.47(0.3)$ & $0.29(0.4)$ & $0.43(0.3)$ \\
\hline \multicolumn{7}{|c|}{$\Delta \operatorname{Renin}(\mathrm{ng} / \mathrm{ml} / \mathrm{h}$ angiotensin $\mathrm{I})$} \\
\hline Month 1 & $-0.02(0.1)$ & $-0.02(0.1)$ & $0.24(0.3)$ & $0.11(0.2)$ & $0.10(0.3)$ & $0.08(0.3)$ \\
\hline Month 3 & $-0.04(0.1)$ & $-0.08(0.1)$ & $0.19((0.2)$ & $-0.08(0.2)$ & $0.01(0.3)$ & $-0.08(0.3)$ \\
\hline Month 6 & $-0.14(0.1)$ & $-0.15(0.1)$ & $0.01(0.3)$ & $0.04(0.3)$ & $-0.02(0.3)$ & $0.01(0.3)$ \\
\hline Month 12 & $-0.04(0.1)$ & $0.02(0.1)$ & $0.29(0.3)$ & $0.26(0.3)$ & $0.04(0.3)$ & $-0.01(0.3)$ \\
\hline
\end{tabular}

Values are least square mean (SEM) (haemodynamics) and log least square mean (SEM) (neurohormones).

${ }^{\star} \mathrm{p}<0.05 ;{ }^{\star \star} \mathrm{p}<0.01 ;{ }^{\star \star \star} \mathrm{p}<0.001$, all $v$ baseline. 

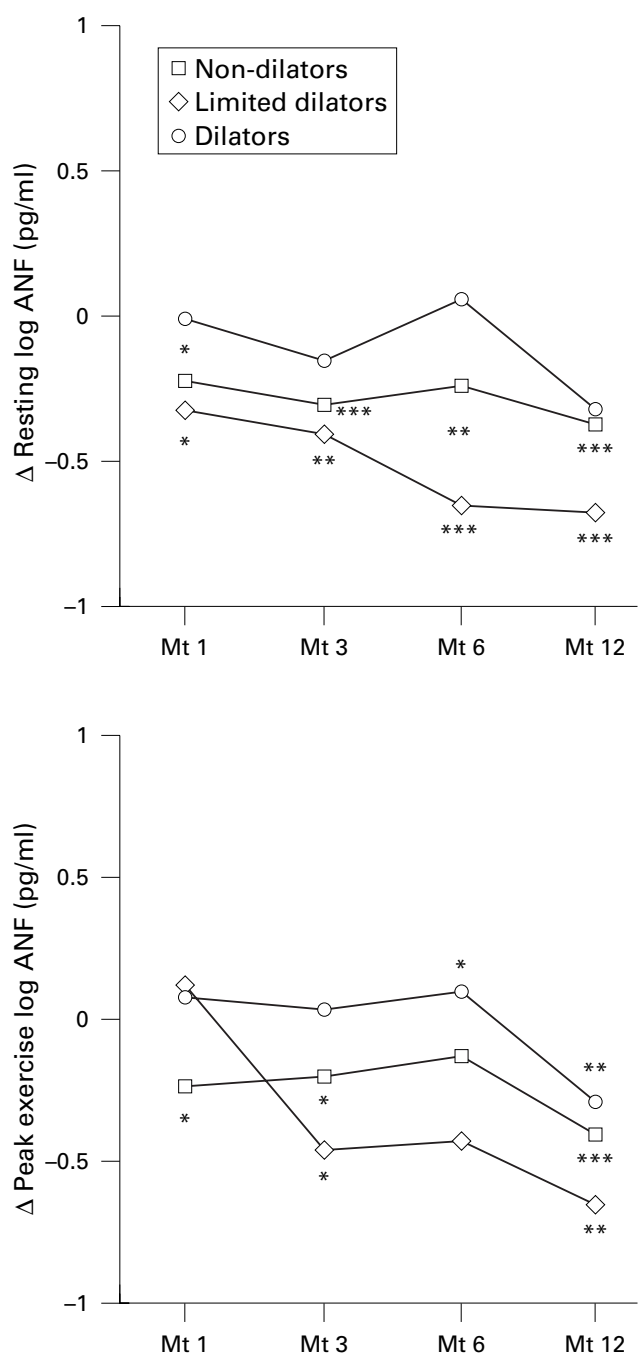

Figure 4 Change in resting and peak exercise log mean atrial natriuretic factor $(A N F)$ after myocardial infarction. ${ }^{\star} p<0.05 ;{ }^{*} p<0.01 ;{ }^{\star \star *} p<0.001$, all $v$ baseline.

The intra-assay coefficient of variation for ANF was $8.6 \%$ and the interassay coefficient of variation $16.8 \%$. The intra-assay and interassay coefficients of variation for renin, noradrenaline, and adrenaline were all less than $10 \%$.

All subjects gave written informed consent and the study received local ethics approval.

\section{STATISTICAL ANALYSIS}

A repeated measures analysis of change from baseline from all patients was used to assess the data up to month 12 . This comprised a mixed model analysis of variance, with factors for ventricular volume group, period of study, and interaction of ventricular volume group with time. This random effects model permits estimation of treatment effects using both within patient and between patient information, and therefore allows the estimation of treatment effects for patients with incomplete profiles on the assumption that the data are missing at random (that is, they are not treatment related). Estimates and within group tests were obtained using residual maximum likelihood (REML). A separate analysis of the effects of all baseline drug treatment on ventricular volume changes was performed; as the $95 \%$ confidence intervals ruled out the possibility of a clinically significant effect, a factor for drug treatment was not considered in subsequent analyses.

In all cases the broad applicability of the statistical model used was assessed by inspection of residual and normal probability plots. Data for the neurohormones were subjected to a logarithmic transformation before analysis. Taking exponents of the least square neurohormonal means from each analysis gives the ratio of the geometric means of post-baseline and baseline values (post-baseline geometric mean/ baseline geometric mean). All statistical tests were two sided and the level of significance was taken to be $5 \%$.

\section{Results}

The demographic data on the patient groups at baseline are shown in table 1 . The numbers of patients receiving thrombolysis and patients with postinfarct angina were equally distributed. A further 11 patients were not included in the study, mainly because of non-compliance or change in concomitant drug treatment (table 2). The baseline characteristics of these patients were not different from those entering the study. Drug treatment at baseline was similar in all patient groups, except for increased use of $\beta$ blockers in patients with limited dilatation (table 1). Analysis of the effects of drug treatment revealed no significant effect on ventricular volumes or haemodynamic and neurohormonal variables.

VENTRICULAR VOLUMES

Ventricular volumes at baseline are shown in table 3. Thirty one patients $(48 \%)$ had high LVEDVI at baseline, but 34 values $(52 \%)$ remained in the normal range. Thirty two patients $(49 \%)$ had high LVESVI at baseline, but 33 patients $(51 \%)$ had values within the normal range. Changes in individual and mean ventricular volumes are shown in figs 1 and 2 . Progressive dilatation was seen in 11 patients $(17 \%)$ and limited dilatation in a further 11 at month 12. In 43 patients (66\%), ventricular volumes were stable or decreased by month 12 (table 3).

\section{EXERCISE STUDIES}

Symptom limited exercise times were shorter at baseline in patients with progressive dilatation (table 1). Mean exercise capacity increased from baseline in all groups, but there were no significant differences between groups up to month 12 (fig 3). All patients were limited by dyspnoea or fatigue; no study was terminated by symptomatic angina.

RELATION BETWEEN VENTRICULAR DILATATION AND HAEMODYNAMIC AND NEUROHORMONAL INDICES

Baseline central haemodynamics, oxygen consumption, and neurohormones are shown in table 4. In patients with no ventricular dilatation, cardiac index at peak exercise increased significantly but remained unchanged at rest (table 5). Stroke volume and 
cardiac index were initially lower in patients with progressive dilatation at rest and during exercise, but these improved over the period of study.

There were trends towards higher levels of $\mathrm{ANF}$ at rest and at peak exercise in patients with progressive dilatation (fig 4). ANF concentrations were significantly reduced from baseline in patients with no and limited dilatation. Plasma noradrenaline increased at peak exercise in patients with no and limited dilatation, although there were no significant changes between groups. Plasma adrenaline and renin activity remained unchanged (table 5).

Maximum heart rate increased in all patients but remained unchanged at rest. Mean arterial pressure was similarly stable during exercise and at rest. There were trends towards higher vascular resistance at baseline in patients with progressive dilatation although this fell during the study. Oxygen consumption at rest was unchanged but increased at peak exercise in all three groups (table 5).

\section{Discussion}

Patterns of ventricular dilatation after acute myocardial infarction are heterogeneous. This is the first study to describe the relation between haemodynamic and neurohormonal indices and ventricular volumes at rest and during symptom limited exercise in the year following acute myocardial infarction. In the majority of patients after myocardial infarction compensatory mechanisms preserve exercise capacity, and ventricular function progressively improves. These changes are associated with a fall in plasma ANF. We have shown that not all patients are susceptible to limited or progressive dilatation, confirming a need for targeted therapeutic intervention after myocardial infarction.

The reasons for the different patterns of ventricular dilatation are unclear. Nearly $50 \%$ of our patients had dilated left ventricles at baseline, although none had severe heart failure. In two thirds of the patients left ventricular volumes remained static or decreased over the first six months of the study. Interestingly these changes were observed in the absence of ACE inhibitors. In approximately one fifth there was either progressive or limited dilatation. It appears difficult to predict which patients will develop progressive dilatation from an assessment of left ventricular size soon after infarction; somewhat surprisingly the patients who went on to develop progressive left ventricular dilatation had smaller ventricles at baseline than those in whom the ventricles did not dilate.

Although it may be argued that these findings reflect regression towards the mean, the use of repeatability coefficients to account for measurement error and intrinsic within subject variability reduces the influence of this phenomenon. Therefore only a small minority of patients with anterior transmural infarction, thought previously to be at high risk of ventricular dilatation, appear to develop significant increases in left ventricular size. These findings confirm those of a similar study in which $20 \%$ of patients developed progressive ventricular dilatation following acute myocardial infarction, ${ }^{5}$ raising the possibility that patients have been treated unnecessarily in some of the recent postinfarction ACE inhibitor trials. ${ }^{16}{ }^{17}$ This might also explain the large numbers of patients required in these studies to show a small mortality benefit.

In the patients with progressive dilatation, cardiac index improved over the period of study, as in the other patient groups. However, the exercise capacity of the patients with progressive dilatation was lower at baseline, with trends towards lower cardiac index and higher vascular resistance. Ventricular dilatation alone acts to restore cardiac function during the early recovery phase of acute myocardial infarction but beyond this period there are limited data. ${ }^{51-28}$ The late increase in ventricular volumes in patients with progressive dilatation was associated with a further increase in stroke volume and cardiac index, suggesting a late compensatory response and preservation of Frank-Starling mechanisms. Late ventricular dilatation, at least up to 12 months, following acute myocardial infarction therefore appears to be beneficial and may be an entirely appropriate physiological response to impaired haemodynamics and reduced exercise capacity. These findings are in keeping with several previous studies, ${ }^{21252628-30}$ although they contrast with the reports from others of impaired haemodynamics and exercise capacity beyond a 12 month period. ${ }^{521}$ This transition from compensated to decompensated left ventricular dilatation warrants further study.

There were no differences in neurohumoral markers at baseline to account for the differences in haemodynamics. Not surprisingly, however, there were trends towards higher levels of ANF in patients with progressive dilatation over the study, both at rest and during exercise. As ventricular volume regressed, ANF concentrations fell in all groups of patients, particularly in those with limited dilatation. Although plasma noradrenaline concentrations increased in patients with no and limited dilatation, catecholamine concentrations were not different between the groups. There are clearly difficulties in interpreting single venous samples of catecholamines but as a marker of sympathetic activation this seems to play little part in the haemodynamic changes observed. Similarly long term activation of the reninangiotensin system, measured by plasma renin activity, appeared unimportant.

This study has some important limitations. First, the patients studied were selected; those with severe heart failure, limiting angina, or positive exercise tests were excluded. Second, the influence of infarct related vessel patency was not directly considered. A patent blood filled vessel is associated with early reperfusion and appears to limit progressive increases in ventricular size. ${ }^{31}{ }^{32}$ In the patients in this study with progressive dilatation there were trends towards a lower rate of thrombolysis, although this was not statistically significant. Finally the significance of our results is limited by the relatively small number of patients overall and 
therefore, by extension, the small numbers of patients in each echocardiographic category.

Despite these limitations, however, our findings suggest that ventricular function improves independently of intervention in the majority of patients following acute myocardial infarction and that progressive dilatation is seen in only a minority. Even in the absence of pharmacological intervention compensatory mechanisms, including ANF release and an increase in ventricular volume, appear capable of maintaining and improving exercise capacity in most patients for at least a 12 month period after acute myocardial infarction.

We thank Dr B Byrom for the statistical analysis and J Richardson and A Felden who performed the echocardiography.

1 Hammermeister KE, DeRouen TA, Dodge HT. Variables predictive of survival in patients with coronary heart disease: selection by univariate and multivariate analyses from the clinical, electrocardiographic, exercise, arteriofrom the clinical, electrocardiographic, exercise, arteriotion 1979;59:421-30.

2 White HD, Norris RM, Brown MA, et al. Left ventricular end-systolic volume as the major determinant of survival after recovery from myocardial infarction. Circulation 1987; 76:44-51.

3 McKay RG, Pfeffer MA, Pasternak RC, et al. Left ventricular remodelling following myocardial infarction: a corollary to infarct expansion. Circulation 1986;74:693-702.

4 Jeremy RW, Allman KC, Bautovitch G, et al. Patterns of left ventricular dilatation during the six months after myocardial infarction. F Am Coll Cardiol 1989;13:304-10

5 Gaudron P, Eilles C, Kugler I, et al. Progressive left ventricular dysfunction and remodelling after acute myocardial infarction. Potential mechanisms and early predictors. Circulation 1993;87:755-63.

6 Franciosa JA, Park M, Levine TB. Lack of correlation between exercise capacity and indexes of resting left ventricular performance in heart failure. Am $f$ Cardiol ventricular perfor $1981 ; 47: 33-9$.

7 Sigurdsson A, Held P, Swedberg K. Short and long term neurohormonal activation following acute myocardial infarction. Br Heart $\mathcal{F}$ 1993;126:1068-76.

8 Sigurdsson A, Swedberg K. Is neurohormonal activation a major determinant of the response to ACE inhibition in left ventricular dysfunction and heart failure? Br Heart $\mathcal{F} 1994$ 72:75-80.

9 Remes JM. Neuroendocrine activation after myocardial infarction. Br Heart $\mathcal{F} 1994 ; 72: 65-9$.

10 Hall C, Rouleau JL, Moye L, et al. N-terminal proatrial natriuretic factor. An independent predictor of long term prognosis after myocardial infarction. Circulation 1994;89: 1934-42.

11 Batin PD, Hawkins M, Cowley AJ. Patterns of neuroendocrine activation at rest and during exercise following acute myocardial infarction. Eur Heart $\mathcal{f} 1994 ; 15: 1552-7$.

12 Sharpe N, Smith H, Murphy J, et al. Treatment of patients with symptomless left ventricular dysfunction after myocardial infarction. Lancet 1988;i:255-9.

13 Jugdutt BI, Warnica JW. Intravenous nitroglycerin therapy to limit myocardial infarct size, expansion and complications: effect on timing, dosage and infarct location. Circulation 1988;78:906-19.
14 Pfeffer MA, Braunwald E, Moye LA, et al on behalf of the SAVE Investigators. Effect of captopril on mortality and
morbidity in patients with left ventricular dysfunction after morbidity in patients with left ventricular dysfunction a
myocardial infarction. $N$ Engl f Med 1992;327:669-77.

15 AIRE Study Investigators. Effect of ramipril on mortality and morbidity of survivors of acute myocardial infarction with clinical evidence of heart failure. Lancet 1993;342: $821-8$.

16 ISIS 4 Collaborative Group. A randomised factorial trial assessing early oral captopril, oral mononitrate, and intravenous magnesium sulphate in 58,050 patients with suspected acute myocardial infarction. Lancet 1995;345: 669-85.

17 GISSI 3 Investigators. GISSI 3: effects of lisinopril and transdermal glyceryl trinitrate singly and together on 6 week mortality and ventricular function after acute week mortality and ventricular function aft
myocardial infarction. Lancet 1994;343:1115-22.

18 Kober L, Torp-Pedersen C, Carlsen JE, et al. A clinical trial of the angiotensin converting enzyme inhibitor trandolapril in patients with left ventricular dysfunction after myocardial infarction. $N$ Engl $\mathcal{F}$ Med 1995;333:1670-6.

19 Cowley AJ, Fullwood LJ, Muller AF, et al. Exercise capability in heart failure: is cardiac output important after all? Lancet 1991;337:771-3.

20 Cowley AJ, Stainer K, Murphy DT, et al. A non invasive method for measuring cardiac output: the effect of Christmas lunch. Lancet 1986;ii:1422-4.

21 McKay RG, Pfeffer MA, Pasternak RC, et al. Left ventricular remodelling following myocardial infarction: a corollary to infarct expansion. Circulation 1986;74:693-702.

22 Gaudron P, Eilles C, Ertl G, et al. Compensatory and noncompensatory left ventricular dilatation after myocardial infarction: time course and haemodynamic consequences at rest and during exercise. Am Heart f 1992;123:377-85.

23 Pierard LA, Albert A, Gilis F, et al. Haemodynamic profile of patients with acute myocardial infarction at risk of infarct expansion. Am f Cardiol 1987;60:5-9.

24 Rahimtoola SH, DiGilio MM, Ehsani A, et al. Changes in left ventricular performance from early after acute myocardial infarction to the convalescent phase. Circulation 1972; 46:770-9.

25 Warren SE, Royal HD, Markis JE, et al. Time course of left ventricular dilatation after myocardial infarction. Influence of infarct-related artery and success of coronary thrombolysis. J Am Coll Cardiol 1988;11:12-19.

26 Picard MH, Wilkins GT, Ray PA, et al. Progressive changes in ventricular structure and function during the year after acute myocardial infarction. Am Heart f 1992;124:24-31.

27 Petersen CL, Gadsboll N, Stadaeger C, et al. Changes in left and right ventricular performance and volumes in seven year survivors of acute myocardial infarction. Am 7 Cardiol 1995;75:659-64.

28 Peels KH, Visser CA, Dambrink JE, et al. Left ventricular wall motion score as an early predictor of left ventricular dilatation and mortality after first anterior infarction treated with thrombolysis. Am 7 Cardiol 1996;77:1149-54.

29 Leung WH, Lau CP. Effect of severity of the residual stenosis of the infarct related coronary artery on left ventricular dilatation and function after acute myocardial infarction. $\mathcal{F}$ Am Coll Cardiol 1992;20:307-13.

30 Silbeberg J, Haichin R, Stewart S, et al. Long term stepwise sustained improvement in left ventricular ejection fraction after myocardial infarction. Am Heart F 1989;117:532-7.

31 Meijer A, Verheught FWA, van Einge MJ, et al. Left ventricular function at 3 months after successful thrombolysis. Impact of reocclusion without reinfarction on ejection fraction, regional function and remodelling. Circulation 1994:90:1706-14.

32 Danchin N, Angioi M, Cador R, et al. Effect of late percutaneous angioplastic recanalisation of total coronary artery occlusion on left ventricular remodelling, ejection fraction and regional wall motion. Am f Cardiol 1996;78:729-35. 